\title{
Low risk, high reward? Repeated competitive biddings with multiple winners in health care
}

\author{
Visa Pitkänen ${ }^{1}\left[\right.$ C Signe Jauhiainen ${ }^{1} \cdot$ Ismo Linnosmaa ${ }^{2,3}$
}

Received: 16 April 2019 / Accepted: 3 December 2019 / Published online: 4 January 2020

(c) The Author(s) 2020

\begin{abstract}
We study physiotherapy providers' prices in repeated competitive biddings where multiple providers are accepted in geographical districts. Historically, only very few districts have rejected any providers. We show that this practice increased prices and analyze the effects the risk of rejection has on prices. Our data are derived from three subsequent competitive biddings. The results show that rejecting at least one provider decreased prices by more than $5 \%$ in the next procurement round. The results also indicate that providers have learned to calculate their optimal bids, which has also increased prices. Further, we perform counterfactual policy analysis of a capacity-rule of acceptance. The analysis shows that implementing a systematic acceptance rule results in a trade-off between direct cost savings and service continuity at patients' usual providers.
\end{abstract}

Keywords Health care $\cdot$ Competitive bidding $\cdot$ Competition $\cdot$ Choice modelling $\cdot$ Prices

JEL Classification C57 $\cdot \mathrm{H} 51 \cdot \mathrm{I} 11 \cdot \mathrm{I} 18$

\section{Introduction}

Public authorities in the European Union spend around 14\% of the GDP on the purchase of services, works and supplies using public procurement [1]. There is an increasing trend also among health and social care organizers to use competitive elements such as competitive biddings [2]. Wellknown imperfect market conditions such as uncertainty and asymmetric information characterize health care markets [3]. Therefore, several issues need to be considered when competitive biddings are used in health care. For example, it is typical to organize the competitive biddings in a repeated manner and select multiple service providers for each contract period. Meanwhile, many patients may receive the service continuously and prefer to visit their usual provider. Competitive biddings give information about the

Visa Pitkänen

visa.pitkanen@kela.fi

1 Research Department, Social Insurance Institution of Finland, P.O. Box 450, 00056 Helsinki, Finland

2 Department of Health and Social Management, University of Eastern Finland, P.O. Box 1627, 70211 Kuopio, Finland

3 Centre for Health and Social Economics, National Institute for Health and Welfare, P.O. Box 30, 00271 Helsinki, Finland right price-level, but the procurement may also change service providers and end long-lasting relationships between patients and providers. Even though these properties are well-known, only very few studies have analyzed the properties of competitive biddings in health care.

In this study, we analyze competitive biddings that were organized by the insurance districts of the Social Insurance Institution of Finland (Kela) in 2003, 2006, 2010, and 2014 to acquire providers for physiotherapy service for disabled individuals. The districts were responsible for acquiring multiple providers based on their quality-price ratio and the local demand for the service. However, the districts did not have strict budget constraints and historically only very few districts rejected any providers. This setting provides an interesting opportunity to examine the properties of repeated competitive biddings with multiple winners in health services. In the main analysis, we study the effects of the risk of rejection on prices. We also perform counterfactual policy analysis, to examine the direct fiscal effects of implementing a systematic capacity-based rule of provider acceptance.

First, we present descriptive evidence and show that the overall price-level of the bids for a 45-min physiotherapy service increased from an average of 33 euros in 2003 to 58 euros in 2014. Meanwhile, the highest bid increased from 55 to 116 euros. Then, we examine more closely the 
effects that the risk of rejection had on prices in the 2010 and 2014 competitive biddings. Our main data sources are quality-price scoring tables collected from the insurance districts, merged with patient-level register data on patients' choice of provider in 2006-2015. We measure the risk of rejection using geographical variation in the insurance districts' rejection rates in previous competitive biddings. We also analyze whether providers' previous distance to the rejection threshold had an effect on their prices. In our analysis, we control for market competition, using measures that are based on the value that each provider brings into the insurance district's network, as well as several other provider and area-level factors.

The results show that rejecting at least one provider decreased prices by more than $5 \%$ in the next competitive bidding. The effect is stronger in 2014 than 2010, which suggests that the providers learned the institutional practices of the procurement procedure. We also find that providers which were located further from the rejection threshold increased their prices more heavily in the next competitive bidding. This indicates that providers learned to calculate their optimal bids, which further increased the overall price-level. These results suggest that implementing a systematic capacity-rule of acceptance in each district would have lowered the overall price-level of the service. We simulate the effects of counterfactual scenarios where providers are accepted based on their annual capacity and the local demand for the service. The analysis shows that the regulation would have decreased the costs especially in the 2014 procurement. However, many patients would have been forced to switch their usual provider, which is problematic in a service that is based on continuous relationships between patients and providers.

The study is related to several distinct strands of literature. First and foremost, the study is related to the use of competitive biddings in health care. We are the first to provide empirical analysis regarding competitive biddings in a health service, which patients receive continuously and for which multiple service providers are acquired in repeatedly organized procurements. Theoretical literature suggests that competitive bidding can be a powerful mechanism to decrease the health care expenditure, but their design and implementation must be done carefully [4, 5]. Empirical literature on competitive biddings in health services is very scarce and comes mainly from the analysis of competitive biddings in the US Studies have shown that insurers can use their market power for higher bids in the competitive biddings of Medicare [6, 7]. Similarly, the results of this study show that price bids have been higher in less competitive areas.

The study also contributes to the literature on the effects of competition on prices in health care. For this purpose, the Finnish physiotherapy markets offer an excellent setting because the market consists of a large number of small private providers. Most of the previous literature has documented that competition decreases prices in hospital services [8]. Pekola et al. [9] analyzed the effects of competition on quality and prices using the same setting with a sample of providers in the 2010 competitive bidding. They found that competition had a weak negative effect on quality but no effect on prices. This study extends their work by taking more precisely into account the historical and institutional setting as well as using a much richer provider and patientlevel data.

The study also relates to provider contracting in health care and the side-effects of narrowing the network from which patients can choose their provider. Higuera et al. [10] show that narrowing the network can reduce costs, but patients are willing to pay for a wider network that includes their usual provider. Similarly, our study illustrates the simple trade-off between economically efficient procurement and continuity of care at the patients' usual provider. Finally, the study provides evidence regarding patient choices and provider quality. Our results are similar to previous literature [11-12], showing that physiotherapy patients choose large, high-quality providers within short distances.

\section{Competitive biddings in health care}

Many countries have implemented policies that increase competition among health care providers [13]. The main purpose of the reforms has been to improve the efficiency and quality of the services. Three main types of provider competition have been presented in the health economics literature: competition in a market, competition for a market and yardstick competition [2]. This paper considers a case where competition both in and for a market is present. Competition in a market usually means that providers compete with quality attributes to attract patients, and the money follows the patients to their selected provider. In this case, prices are often fixed, and the organizer needs to determine the appropriate price-level. To choose, patients should have several alternative providers and access to quality information. Nevertheless, patient choice has become very common in primary health services in European countries [14], and there is increasing empirical evidence showing that quality influences patient choices [11, 15].

Competition for a market means that several potential providers compete for the right to provide services or goods. The purchaser selects one or more providers in, for example, a geographical area. Common examples include the purchasing of pharmaceutical products or hospitals competing to be included in an insurer's network of providers. Competition for a market requires that the service organizer can describe the services or goods in an accurate and verifiable way [2]. 
Providers and their prices can be determined, for example, using competitive bidding or bargaining between the purchaser and provider. Compared to fixed prices, competitive bidding provides information about both the prices and the providers that deliver the services at the lowest prices [16]. Therefore, competitive biddings have gained an increasingly important role in discussions about the future financing of health care services [7, 17].

Public procurements and auctions often work very well, but their design must be sensitive to the details of the institutional setting [18]. According to McCombs and Christianson [19], competitive bidding where multiple providers are selected has following four main advantages: first, selecting more than one provider gives flexibility and ensures service availability in cases where a provider exits the market or the demand suddenly increases during the contract period. Second, it might encourage more providers to participate in the procurement, because it increases the probability of being included in the pool of providers. Third, it provides patients a larger degree of choice from the pool of providers, which in turn might increase quality competition in the market among providers. Fourth, accepting multiple providers might ensure market competitiveness in subsequent competitive biddings by preserving viable competitors.

McCombs and Christianson [19] also point out three potential disadvantages: first, in areas where the number of potential providers is very small, there are only weak incentives to submit low bid prices, because the probability of losing is very low. Second, adverse selection problems under a per-episode reimbursement scheme may occur, because the price does not vary but some patients may require more intensive care. Therefore, some providers might try to avoid taking the most demanding patients. Third, accepting a large number of providers might decrease providers' expectations of number of potential patients and gains from economies of scale, reducing the number of low price bids.

McCombs and Christianson [19] also discuss how the line between accepted and rejected providers should be drawn. A potential procedure is to use a capacity-based rule of acceptance, which requires that all providers submit a maximum capacity of service they can provide during the course of their contract. Accepted providers are then selected in an ascending order of bids, based on the possible quality-price rule, until the target capacity is reached. Under these conditions, the procurement results in a number of providers that ensures access to the services and the long-run market competitiveness. However, if a strict and clear rule of acceptance is not used, providers have strong incentives to "game" the system by submitting bids that are higher than their costs but lower than their estimate of the lowest possible rejected bid. ${ }^{1}$ McCombs and Christianson [19] hypothesize that the "gaming" will eventually increase the overall price-level of the bids. Our study empirically tests this hypothesis.

\section{Institutional setting}

The institutional setting of the study is an individual outpatient physiotherapy service, which is part of the intensive medical rehabilitation services financed and organized by Kela. The physiotherapy is intended for disabled persons under 65 years of age, who face problems managing daily activities and fulfill the criteria defined by law. The basis of the service is a written rehabilitation plan that is drawn up with a physician for 1-3 years at a time. Patients do not pay any out-of-pocket payments and have a free choice of provider from the pool of accepted providers. Typically, patients receive sessions that last for 45 or $60 \mathrm{~min}$, a couple times a week for several years. The physiotherapy is received either at the provider's facilities or at patient's home. 14,756 patients received the service in 2015 , and the total costs were 73.5 million euros [21].

Kela acquires the service from private physiotherapy providers. Physiotherapy markets are among the most competed health services in Finland. Based on Statistics Finland's registers there were 2632 independent physiotherapy providers that had 3655 employees and annual turnover of 302 million euros in 2015. Meanwhile, Kela purchased the service from 1253 different providers in 2015. Thus, around 48\% of all physiotherapy providers in Finland are Kela's service providers and the service covers around $24 \%$ of the sector's annual turnover. Overall, Kela is the largest single financer of different rehabilitation services in Finland. Other large purchasers of physiotherapy services for different patient groups are municipalities, the occupational health care sector and insurance companies. Compared to the physiotherapy services organized by municipalities and other financers, patients who receive the service organized by Kela have more severe disabilities and require more intensive therapy. ${ }^{2}$ Individuals can also visit private physiotherapists by paying out-of-pocket payments. ${ }^{3}$ Usually patients do not simultaneously receive the rehabilitation services that are financed by different organizations.

Kela's insurance districts are responsible for organizing the service for the local population. The districts acquire the

\footnotetext{
1 This behavior is similar to tacit collusion in repeated auctions [20].

${ }^{2}$ Some patients may have received physiotherapy organized by their municipality before Kela accepts their rehabilitation plan or after they turn 66 years and are not entitled to the service organized by Kela.

${ }^{3}$ If patients have a referral from the doctor, they are entitled to a small reimbursement paid by Kela from the National Health Insurance.
} 


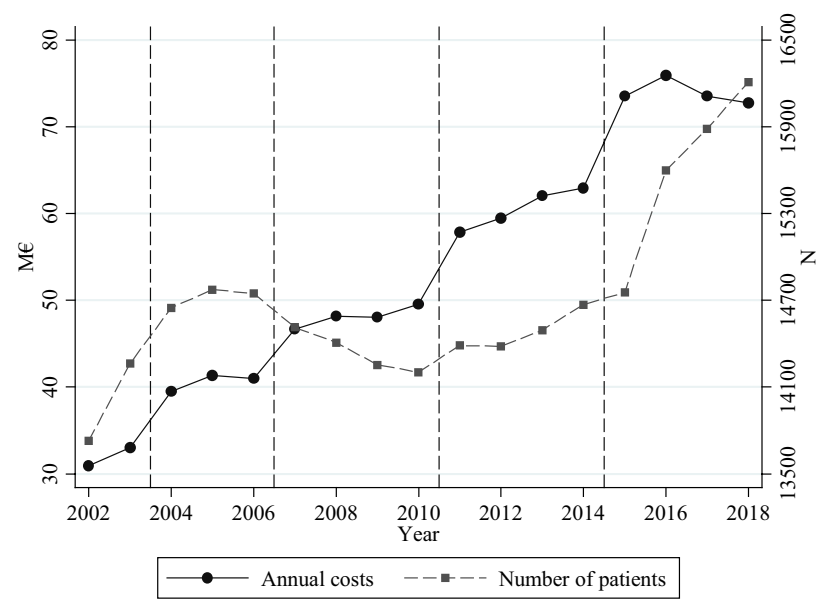

Fig. 1 Number of patients and annual costs of the service in 20022018. Vertical dashed lines present a change in the contract periods. Presented costs are nominal

service from private physiotherapy providers using a competitive bidding, ${ }^{4}$ which they have organized in a similar and predefined manner since $2003 .{ }^{5}$ Most of the districts negotiated prices directly with the providers prior to 2003 . $^{6}$ The three latest competitive biddings were organized in 2006, 2010 and 2014 for the contract periods 2007-2010, 2011-2014, and 2015-2018. Figure 1 presents the annual nominal costs of the service and the number of patients in 2002-2018. The figure shows that while the number of patients remained relatively stable before the latest contract period, the annual nominal costs more than doubled. The largest cost increase took place in the first year of each contract period, when new prices were set. The number of patients has increased by around $10 \%$ during the latest contract period. However, there has been no increase in total costs. This indicates that the annual number of physiotherapy sessions per patient has decreased, most likely as a result of financial pressures caused by the rising costs.

The procurement process begins with a request for tenders. Providers provide information on their quality, annual capacity and set a price for a 45-min physiotherapy session in their tenders. The tenders are submitted to the insurance district where the providers are based. The districts evaluate the tenders and rank the providers that meet the minimum

\footnotetext{
${ }^{4}$ Other large physiotherapy purchasers such as municipalities also use repeated competitive biddings, and there may be spillover effects in the procurements between the different markets because many providers are present in the different markets. However, we do not have data on other procurements and the focus is therefore in the markets organized by Kela.

5 Exceptions are South Ostrobothnia and Päijät-Häme districts that implemented a fixed price pilot in the 2011-2014 contract period.

${ }^{6}$ Unfortunately, data on prices prior to 2003 was not available.
}

criteria based on their quality-price scores. ${ }^{7}$ Each district decides a rejection threshold based on the capacity of the providers and estimated local demand for the service. The district manager approves this threshold. Providers above the threshold are offered a 4-year contract, and providers that sign the contract form a pool of providers from which patients can freely choose their provider. However, quality information on the providers is not publicly available. Providers are paid for patients' visits based on their accepted prices. Since the 2006 competitive bidding, the districts have sent the quality-price ranking lists to each provider that submitted a tender in that district. ${ }^{8}$ Providers were also always given information about the quality score rules, and they were able to calculate their points from the information they provided to the district. Figure 3 (in the Appendix) presents an example of the quality-price score table that was used in the Espoo district in 2014.

Even though the districts were expected to accept providers based on local demand and providers' capacity, the most common rejection threshold has been below the provider ranked last. Figure 2 shows the districts that rejected at least one provider in 2006, 2010 and 2014. In 2006 there were five districts that rejected 11 providers, in 2010 only three districts that rejected seven providers and in 2014 six districts that rejected 28 providers. Altogether only $1.2 \%$ of the providers got rejected in the three studied competitive biddings (46 out of 3769). Most of the rejected providers were single outliers, which means that they either offered a significantly high price or had a very low quality. For most of the providers the risk of being rejected was very low, which enabled them to raise prices after realizing this institutional practice. All districts acquired multiple times their required capacity in every competitive bidding. For example, in 2014 the total capacity of the accepted providers was 50,917 whereas only 14,671 patients received the service.

Based on interviews with Kela procurement personnel, there were four main reasons why the districts did not reject more providers: first and foremost, Kela is obliged by law to organize the service nationwide for all eligible patients, and the districts have needed to ensure the availability of the service also in rural parts of the country. Second, the district managers did not have a budget constraint or price limit when they decided on the threshold. Third, Kela has emphasized patients' freedom to choose from a large pool of providers. Finally, the districts have wanted to avoid a situation where a large number of patients are forced to switch

\footnotetext{
7 In 2006, the quality-price scoring rule was quality/price, in 2010 quality was weighted $60 \%$ and price $40 \%$, whereas in 2014 quality and price were both weighted $50 \%$.

8 The quality-price score tables have been available from the districts also later on.
} 


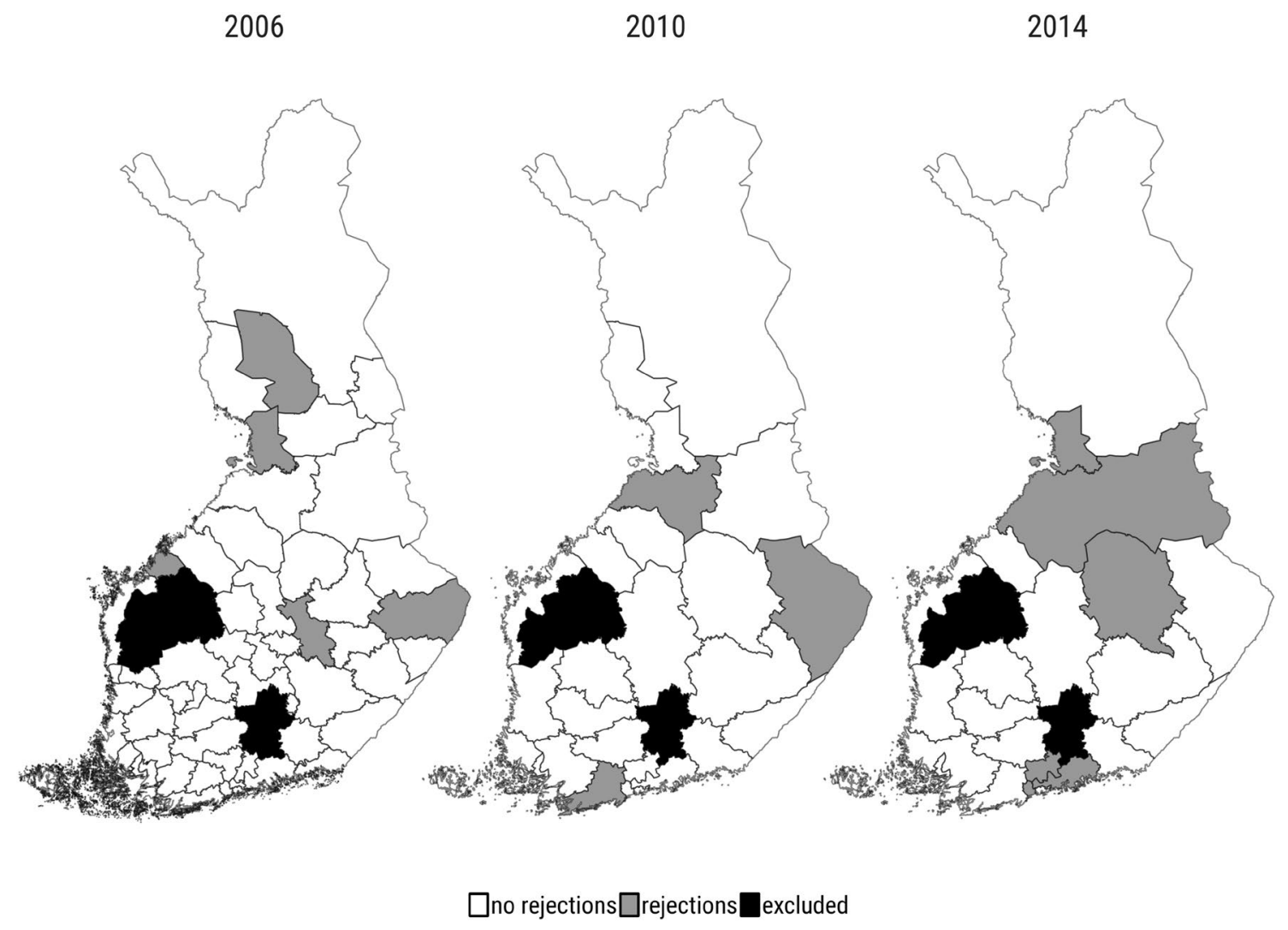

Fig. 2 Rejections across the districts in the 2006, 2010 and 2014 competitive biddings. A price regulation pilot took place in South Ostrobothnia and Päijät-Häme districts in the 2011-2014 contract

providers because their previous provider was not accepted in the new pool of providers. In conclusion, the district managers did not have proper incentives to reject providers because no financial pressure existed, and rejections would have likely resulted in an increase in administrative work and negative feedback.

\section{Data}

\section{Provider-level data}

Our main provider-level data sources are quality-price score lists that were collected from insurance districts that organized the competitive biddings in 2006, 2010 and 2014. The lists include quality scores, price bids for 45-min service and annual capacities of all providers that fulfilled the minimum requirements and were ranked based on their quality-price scores. ${ }^{9}$ The data include information on the

\footnotetext{
${ }^{9}$ Unfortunately we do not have data about bids that did not meet the minimum requirements.
}

period. Therefore, providers in these districts did not participate in the 2010 competitive bidding and have been excluded from our analysis

rejection threshold that each insurance district decided upon. We also have data on providers' accepted prices in the 2003 competitive bidding, which was the first procurement organized similarly in all districts. ${ }^{10}$ Our data also include the providers' address, postcode and business type information.

Measuring provider quality is challenging because quality is very multidimensional in health care [22]. Quality measures are often based on inputs such as number of staff per beds, or outcomes such as 30-day mortality. The districts measured physiotherapy providers' quality through their investments in three main categories: education, experience and facilities. Certain other minor issues, such as language skills, also factored in. As in Forder and Allan [23], our measure of quality can be seen as a proxy for providers' underlying performance quality or utility gain construct.

Kela implemented a fixed-price pilot in two insurance districts (South Ostrobothnia and Päijät-Häme) in the 2011-2014 contract period. We have excluded these two districts from our data and analysis. This should not result

\footnotetext{
10 The 2003 data is based on a list of providers' accepted prices in
} November 2006. 
Table 1 Descriptive statistics of the providers in 2003, 2006 , 2010 and 2014

\begin{tabular}{|c|c|c|c|c|c|c|c|c|c|c|}
\hline \multirow[t]{2}{*}{ Variable } & \multicolumn{5}{|c|}{ Accepted providers } & \multicolumn{5}{|c|}{ Rejected providers } \\
\hline & $N$ & Mean & SD & Min & Max & $N$ & Mean & SD & Min & Max \\
\hline \multicolumn{11}{|l|}{2003} \\
\hline Price $(€)$ & 1364 & 33.41 & 4.52 & 20 & 55 & - & - & - & - & - \\
\hline \multicolumn{11}{|l|}{2006} \\
\hline Price $(€)$ & 1369 & 39.13 & 5.82 & 21 & 71 & 11 & 41.95 & 8.00 & 30 & 55 \\
\hline Quality & 1283 & 67.13 & 12.06 & 28 & 103 & 11 & 58.18 & 16.58 & 24 & 78 \\
\hline Quality-price score & 1283 & 77.07 & 8.46 & 44.38 & 100 & 11 & 71.83 & 12.58 & 54.71 & 100 \\
\hline Capacity & 530 & 17.50 & 20.19 & 1 & 200 & - & - & - & - & - \\
\hline Premises & 1369 & 0.91 & 0.29 & 0 & 1 & 11 & 0.73 & 0.47 & 0 & 1 \\
\hline New provider & 1369 & 0.18 & 0.39 & 0 & 1 & 11 & 0.55 & 0.52 & 0 & 1 \\
\hline Patients & 1369 & 8.81 & 12.86 & 0 & 152 & 11 & 2.45 & 4.16 & 0 & 13 \\
\hline$\Delta$ Price $(€)$ & 1119 & 5.50 & 3.49 & -21 & 32.9 & 5 & 6.1 & 6.19 & 2 & 17 \\
\hline \multicolumn{11}{|l|}{2010} \\
\hline Price $(€)$ & 1195 & 47.54 & 7.62 & 28 & 99 & 7 & 54.07 & 10.22 & 35 & 68.5 \\
\hline Quality & 1195 & 80.46 & 13.63 & 31 & 104 & 7 & 68.29 & 16.01 & 44 & 84 \\
\hline Quality-price score & 1195 & 79.15 & 8.14 & 40 & 100 & 7 & 70.37 & 5.86 & 59.7 & 76.4 \\
\hline Capacity & 1195 & 33.77 & 43.40 & 1 & 420 & 7 & 40.14 & 67.95 & 5 & 192 \\
\hline Premises & 1195 & 0.92 & 0.27 & 0 & 1 & 7 & 0.86 & 0.38 & 0 & 1 \\
\hline New provider & 1195 & 0.14 & 0.35 & 0 & 1 & 7 & 0.57 & 0.53 & 0 & 1 \\
\hline Patients & 1195 & 10.19 & 14.10 & 0 & 161 & 7 & 1.14 & 2.61 & 0 & 7 \\
\hline$\Delta$ Price $(€)$ & 1013 & 8.12 & 5.05 & -27.5 & 32 & 2 & 10 & 4.24 & 7 & 13 \\
\hline \multicolumn{11}{|l|}{2014} \\
\hline Price $(€)$ & 1159 & 57.83 & 9.43 & 34 & 102.5 & 28 & 70.38 & 16.80 & 45 & 116 \\
\hline Quality & 1159 & 37.41 & 7.45 & 9 & 55 & 28 & 26.57 & 7.39 & 14 & 43 \\
\hline Quality-price score & 1159 & 73.45 & 7.69 & 41.88 & 100 & 28 & 57.15 & 5.45 & 39.68 & 67.17 \\
\hline Capacity & 1159 & 40.99 & 53.73 & 1 & 450 & 28 & 13.64 & 13.83 & 2 & 70 \\
\hline Premises & 1159 & 0.92 & 0.27 & 0 & 1 & 28 & 0.71 & 0.46 & 0 & 1 \\
\hline New provider & 1159 & 0.18 & 0.38 & 0 & 1 & 28 & 0.61 & 0.50 & 0 & 1 \\
\hline Patients & 1159 & 10.85 & 16.08 & 0 & 179 & 28 & 1.29 & 2.73 & 0 & 12 \\
\hline$\Delta$ Price $(€)$ & 923 & 10.07 & 5.80 & -16 & 54.5 & 11 & 15.62 & 12.80 & 1.58 & 40 \\
\hline
\end{tabular}

$\Delta$ Price includes providers that submitted a bid also in the previous round. Providers in the districts where a price regulation pilot took place in 2011-2014 are excluded from the data in any bias because the districts are responsible for organizing the service only for the local population and they can be considered as independent geographical entities. In total, our final data include information about 5133 bids from four consecutive competitive biddings. The descriptive statistics of the accepted and rejected providers in the studied competitive biddings are presented in Table 1 .

\section{Patient-level data}

The patient-level data are based on Kela's registers on rehabilitation applications and invoices regarding patients who received the service in 2006-2015. The applications data contain patients' age, sex, municipality, postcode and ICD-10 codes of primary, secondary and tertiary illnesses. The data also include information on whether the patient had the right to receive the service at home, the number of annual physiotherapy sessions and the length of the sessions in minutes. We have merged the applications data with invoices. Providers were instructed to invoice Kela once a month, and therefore the data include on average 10 invoices for each patient. The invoice data also include information on whether the patient received the service at home, based on whether a provider was paid extra for travelling. We have calculated an annual cost per patient based on the selected provider's price, the number of annual sessions and whether the service was received at home or at the provider's facilities. Similar to our provider-level data, we have excluded all patients who resided in the two districts where the fixedprice pilot was implemented in the 2011-2014 contract period. Table 2 presents the descriptive statistics of the patients and their choice sets in 2011 and 2015. 
Table 2 Descriptive statistics of patients in 2011 and 2015

\begin{tabular}{|c|c|c|c|c|c|c|c|c|c|c|}
\hline \multirow[t]{2}{*}{ Variable } & \multicolumn{5}{|l|}{2011} & \multicolumn{5}{|l|}{2015} \\
\hline & $N$ & Mean & SD & Min & $\operatorname{Max}$ & $N$ & Mean & SD & Min & $\operatorname{Max}$ \\
\hline Age & 12,728 & 38.61 & 20.35 & 0 & 66 & 13,045 & 37.42 & 20.42 & 0 & 66 \\
\hline Male & 12,728 & 0.51 & 0.50 & 0 & 1 & 13,045 & 0.51 & 0.50 & 0 & 1 \\
\hline Sessions at home & 12,728 & 0.40 & 0.49 & 0 & 1 & 13,045 & 0.54 & 0.50 & 0 & 1 \\
\hline Number of sessions & 12,728 & 56.80 & 25.83 & 5 & 150 & 13,045 & 54.19 & 25.55 & 5 & 150 \\
\hline Length of a session (min) & 12,728 & 57.47 & 7.22 & 30 & 120 & 13,045 & 57.61 & 7.10 & 30 & 90 \\
\hline Number of illnesses & 12,728 & 1.69 & 0.81 & 1 & 3 & 13,045 & 1.89 & 0.85 & 1 & 3 \\
\hline Provider's quality & 12,728 & 87.69 & 10.69 & 31 & 104 & 13,045 & 41.50 & 5.98 & 9 & 55 \\
\hline Distance to provider $(\mathrm{km})$ & 12,728 & 11.18 & 13.65 & 0.5 & 177.29 & 13,045 & 12.21 & 15.69 & 0.5 & 190.18 \\
\hline Provider in same district & 12,728 & 0.91 & 0.28 & 0 & 1 & 13,045 & 0.90 & 0.29 & 0 & 1 \\
\hline Providers in same district & 12,728 & 50.23 & 16.96 & 4 & 84 & 13,045 & 56.46 & 17.66 & 4 & 96 \\
\hline Providers in choice set & 12,728 & 125.88 & 86.87 & 4 & 335 & 13,045 & 128.08 & 78.36 & 4 & 359 \\
\hline Annual costs $(€)$ & 12,728 & 4139 & 2358 & 275 & 17,280 & 13,045 & 5124 & 3034 & 287.5 & 25,888 \\
\hline Total costs $(€)$ & $52,676,311$ & & & & & $66,847,118$ & & & & \\
\hline
\end{tabular}

Patients in the districts where a price regulation pilot took place in 2011-2014 are excluded from the data

\section{Other data sources}

We use open postcode data from Statistics Finland and have calculated straight-line distances between patients' and providers' postcodes. The calculations are based on the distances between the centre points of the postcodes. ${ }^{11}$ We also use Statistics Finland's postcode-level register data that include the number of private physiotherapy providers in each postcode in 2006-2015, as well as data on average rents in each postcode in 2010-2015 that is based on Kela's housing benefit registers for free market rents. Finally, we also have municipal-level register data on the number of individuals who were eligible for Kela's rehabilitation services for disabled persons in 2006-2015.

\section{Empirical approaches}

\section{Measures of risk}

Each provider faces a risk of rejection in a competitive bidding when the procurer uses systematic acceptance criteria, for example based on local demand and providers' capacity. However, as explained in Chapter 3 and illustrated in Fig. 2, Kela insurance districts did not apply a systematic acceptance rule. This institutional feature gives us a possibility to

\footnotetext{
11 We use a distance of 0.5 kilometres when patient and provider were located in the same postcode. The smallest distance between two independent postcodes in our data is 0.93 kilometres. Unfortunately, we did not have access to data on actual travel times between postcodes.
}

use the variation across the insurance districts' rejections in the previous competitive biddings, to measure the risk of rejection. We introduce two different measures of risk. First, we create a binary variable "rejections", which receives a value 1 if the provider is located in a district that rejected at least one bid in the previous competitive bidding, and 0 otherwise. The measure indicates whether the providers have learned to anticipate the possibility for rejections in their district, as previous quality-price scoring tables were publicly available. At least one provider was rejected only in five districts out of the 53 districts in 2006, whereas in 2010 rejections were made only in three districts out of the 27 districts.

When a profit-maximizing provider decides on the price it bids, the provider will most likely make some assumptions about the highest price it could bid, considering its quality score, and still be accepted. ${ }^{12}$ The provider can learn its optimal price afterwards, when it receives the quality-price score table from the district. As our second measure of risk, we exploit this feature and calculate providers' distance to the rejection threshold in the previous competitive bidding, measured in quality-price scores. ${ }^{13}$ The distance to the threshold is measured to the lastly accepted provider, also in the districts where all providers were accepted. The intuition

\footnotetext{
${ }^{12}$ We acknowledge that the physiotherapy market has many not-forprofit providers.

13 The quality-price score was calculated simply as quality/price in 2006. We have transformed this into a similar quality-price measure as in 2010 and 2014 using weights of $50 \%$ for both quality and price. This does not change the original order of the providers in the districts' score tables and makes the results comparable in the different competitive biddings.
} 
Table 3 Measures of risk and competition in the 2010 and 2014 competitive biddings

\begin{tabular}{|c|c|c|c|c|c|c|c|c|c|c|}
\hline \multirow[t]{2}{*}{ Variable } & \multicolumn{5}{|l|}{2010} & \multicolumn{5}{|l|}{2014} \\
\hline & $N$ & Mean & SD & Min & $\operatorname{Max}$ & $N$ & Mean & SD & Min & $\operatorname{Max}$ \\
\hline \multicolumn{11}{|l|}{ Measures of risk } \\
\hline Rejections & 1202 & 0.12 & 0.32 & 0 & 1 & 1187 & 0.09 & 0.29 & 0 & 1 \\
\hline Distance to threshold & 964 & 12.76 & 7.40 & 0 & 42.64 & 934 & 18.31 & 9.51 & -9.10 & 49 \\
\hline \multicolumn{11}{|l|}{ Measures of competition } \\
\hline Predicted HHI & 1202 & 455.38 & 274.93 & 233.72 & 2608.42 & 1187 & 413.51 & 308.74 & 165.79 & 3208.39 \\
\hline Actual HHI & 1202 & 537.62 & 248.43 & 239.78 & 1840.90 & 1187 & 552.07 & 348.66 & 203.58 & 3310.22 \\
\hline
\end{tabular}

Measures of risk are based on lagged values from the previous competitive bidding

behind the measure is following: providers that were highly ranked (far above the threshold) could have bidded a higher price, and therefore might be able to take more risk in the next competitive bidding. In turn, providers that had a relatively low rank (near the threshold) or were rejected might take less risk in their next price bid. ${ }^{14}$ This measure only applies to providers who also participated in the previous competitive bidding, as they were able evaluate their optimal bids compared to other providers.

The decisions about the acceptance thresholds in each district are made by local Kela officials. Also, a provider's rank in the quality-price table is influenced by all other bids in the district. Therefore, we consider both the "rejections" as well as the "distance to the threshold" variables to be exogenously determined for a single provider. One potential source of endogeneity could be that Kela officials in geographically small districts with a large number of potential service providers could have rejected providers more easily. Table 8 (in the Appendix) shows descriptive statistics regarding the districts with and without rejections in the 2006 and 2010 competitive biddings. Based on the data, there seems to be no systematic difference between the districts that rejected bids and those that did not. In particular, the statistics prove that there was no systematic quality-price threshold used in the districts. In addition, correlations between rejections and geographical size $(r=$ $0.02)$ or the number of bidders $(r=0.13)$ are very small at the district-level.

Descriptive statistics regarding the two measures of risk are shown in Table 3. In the 2010 competitive bidding 12\% of the providers were located in an area where at least one rejection was made previously, and in 2014 the proportion

\footnotetext{
${ }^{14}$ Figure 3 (in the Appendix) illustrates the intuition: The highest ranked provider received 45 quality points and offered a price of 58 euros. The provider receives the quality-price scoring table after the procedure and notices that many providers with the same or lower quality points offered a higher price and received a contract. Thus, it is likely that this provider will bid a higher price in the next round compared to a provider with lower rank.
}

was $9 \%$. The average distance to the rejection threshold was 12.7 quality-price points in 2010 and 18.3 points in 2014 .

\section{Measures of competition}

Greater competition might decrease prices also in competitive biddings. Because there is no generally agreed measure of market structure, we use two measures to show that our results are robust across the main approaches used in the previous empirical literature. We calculate Herfindahl-Hirschman Indexes (HHI) that are based on providers' actual and predicted market shares within their insurance district. We transform both indexes into a negative natural logarithm, which eases the interpretation of the results, as $-\ln (\mathrm{HHI})$ increases with more competition. The index is calculated in a district $d$ at year $t$ in the following way:

$-\ln \left(\mathrm{HHI}_{d t}\right)=-\ln \sum_{j=1}^{j}\left(\frac{n_{j}}{N_{d}}\right)^{2}$

where $n_{j}$ is the number of actual or predicted patients at provider $j$ and $N_{d}$ is the number of patients in a district $d$.

Defining markets with geographic boundaries often has its problems as postcodes are likely to be too small and some other boundaries too large [24]. Our preferred definition of the relevant market is the insurance district, because they were responsible for organizing the service for the local population and accepting the providers in the competitive biddings. However, measures of market structure based on concentration and geographical boundaries suffer from wellknown endogeneity issues in price regressions. For example, the location of the providers and of new market entrants might be associated with prices. Also, higher quality providers may attract more patients and have higher market shares, resulting in a higher HHI for their market. Because these providers usually also have higher prices, this can lead to an estimated positive relationship between price and concentration measure driven by omitted quality scores rather than by market power [25]. This should not be a problem in our 
setting, as we are able to control for providers' quality in our price regressions.

There might be also other issues that are related to both competition and prices that we cannot fully control. Kessler and McClellan [26] have provided the most common strategy to mitigate the endogeneity bias. They estimate a choice model to predict patient flows among providers, and calculate market concentrations using these predicted rather than actual patient flows. We follow their strategy and calculate $-\ln (\mathrm{HHI})$ that is based on providers' predicted market shares in their insurance districts. This approach to measuring competition has also been used previously [27, 28]. Descriptive statistics regarding the competition measures are also presented in Table 3. In the price regressions we prefer to use the measure of competition based on predicted flows, and the results based on actual flows are shown in the Appendix.

\section{Patient choice modelling}

We begin the calculations of predicted patient flows by estimating choice models on patient choices in 2011 and 2015. We use a standard random utility choice model by McFadden [29] and assume that patients are rational and maximize their utility when choosing a provider. The relative utility for a patient $i$ at provider $j$ at time $t$ is described as:

$U_{i j t}=V_{i j t}+e_{i j t}=\beta_{q} Q_{j t}+\beta_{d} D_{i j}+\beta_{\left(d^{2}\right)} D_{i j}^{2}+\beta_{c} C_{j t}+e_{i j t}$,

where $V_{i j t}$ represents the observable utility, which depends on the provider's quality $Q_{j t}$, distance $D_{i j}$, squared term of distance $D_{i j}^{2}$, and capacity $C_{j t}$. We allow patients' preferences to vary according to observed characteristics such as their age, gender and rehabilitation background. The marginal utility of quality for patient $i$ is:

$\beta_{q i}=\beta_{q}+\beta_{q} X_{i}^{\prime}$,

and similar for distance and capacity.

Patients choose from a set of alternative providers $N_{j t}$. We have created choice sets that include all accepted providers in the patients' insurance districts and all other providers within 80 kilometres. Provider $j$ is chosen if it results in the highest utility in the choice set. We assume that the error term $e_{i j t}$ is independently and identically distributed (IID) with a type-1 extreme value distribution, which leads to a conditional logit model where the probability that a patient $i$ selects provider $j$ is:

$$
\operatorname{Pr}_{i j t}=\frac{\exp \left(V_{i j t}\right)}{\sum_{j^{\prime} \in M_{i t}} \exp \left(V_{i j^{\prime} t}\right)}
$$

The results of the patient choice models for years 2011 and 2015 are found in Table 4. In general, our main results are very similar to previous empirical literature on patient choice [11-12], showing that patients prefer large, highquality providers within close distance. The patients' heterogeneity is captured through the interaction terms in the model, indicating that older patients are not as sensitive to quality differences between providers and prefer shorter distances. We also find that patients who receive the service at their home choose providers from longer distance, which is intuitive as they do not bear the cost of extra travel-time. The results also provide an important policy-relevant point regarding the studied market: Even though the districts did not stimulate competition for the markets by rejecting a sufficient number of providers, patient choice has encouraged quality-competition among the selected providers in the market.

We use the estimates of the choice models and predict provider $j$ 's market share in its district in the year of the competitive bidding, by summing up patients' estimated choice probabilities for choosing provider $j$ in 2010 and 2014. We use the estimates from the 2011 choice model for predicted choices in 2010 and similarly estimates from the 2015 model for predicted choices in 2014. For the predictions we use choice sets that cover all providers in patient $i$ 's insurance district. We measure the goodness-of-fit of our model by comparing the predicted results against patients' actual choices. We follow previous literature [30-32] and calculate a "hit-or-miss" variable where predicted choice for a patient is the provider that has the greatest predicted probability. This analysis shows that our model correctly predicts $28.0 \%$ of the choices in 2011 and $26.6 \%$ in 2015 . These prediction rates are comparable to the previous studies. As the demand model predicts choices well, the correlation between the HHI based on actual and predicted patient flows $(r=0.670)$ is also strong.

\section{Price equations}

We estimate two different linear regression models to analyze the effects of risk on prices. The first model is the following:

$\ln \left(P_{j d t}\right)=\beta_{0}+\beta_{1} R_{j t}^{r}+\beta_{2} H_{j d t}+\beta_{3} Z_{j t}+\beta_{4} X_{p m t}+\beta_{j d t}$,

where the dependent variable $\ln \left(P_{j d t}\right)$ is a natural logarithm of provider $j$ 's price in district $d$ in the competitive bidding organized at time $t$. The key variable of our interest is the risk measure $R_{j t}^{r}$, which receives value 1 if the provider is located in an area where at least one rejection was done in the previous round, and 0 otherwise. The second empirical model takes the following form: 
Table 4 Conditional logit models of patient choices in 2011 and 2015

\begin{tabular}{|c|c|c|c|c|}
\hline \multirow[t]{2}{*}{ Variable } & \multicolumn{2}{|l|}{2011} & \multicolumn{2}{|l|}{2015} \\
\hline & Est & $\mathrm{SE}$ & Est & SE \\
\hline \multicolumn{5}{|l|}{ Main effects } \\
\hline Quality & 0.085 & $0.004 * * *$ & 0.130 & $0.007 * * *$ \\
\hline Distance & -0.144 & $0.005 * * *$ & -0.120 & $0.004 * * *$ \\
\hline Distance $^{2}$ & 0.0004 & $0.000 * * *$ & 0.0001 & $0.000 * * *$ \\
\hline Capacity & 0.005 & $0.0005 * * *$ & 0.004 & $0.000 * * *$ \\
\hline \multicolumn{5}{|l|}{ Interaction with quality } \\
\hline$\times$ Age & -0.001 & $0.000 * * *$ & -0.001 & $0.000 * * *$ \\
\hline$\times$ Male & -0.003 & 0.002 & -0.007 & $0.003 *$ \\
\hline$\times$ Number of annual sessions & -0.000 & 0.000 & 0.0001 & 0.0001 \\
\hline$\times$ Number of illnesses & -0.0001 & 0.001 & -0.003 & 0.002 \\
\hline$\times$ Sessions at home & 0.005 & $0.002 *$ & -0.006 & 0.004 \\
\hline \multicolumn{5}{|l|}{ Interaction with distance } \\
\hline$\times$ Age & -0.001 & $0.000 * * *$ & -0.0005 & $0.0001 * * *$ \\
\hline$\times$ Male & 0.002 & 0.002 & 0.002 & 0.002 \\
\hline$\times$ Number of annual sessions & 0.0002 & $0.0001 * *$ & -0.0001 & 0.0001 \\
\hline$\times$ Number of illnesses & 0.008 & $0.001 * * *$ & 0.005 & $0.001 * * *$ \\
\hline$\times$ Sessions at home & 0.018 & $0.003 * * *$ & 0.019 & $0.002 * * *$ \\
\hline \multicolumn{5}{|l|}{ Interaction with capacity } \\
\hline$\times$ Age & 0.0001 & $0.000 * * *$ & 0.0001 & $0.000 * * *$ \\
\hline$\times$ Male & 0.0001 & 0.0002 & 0.0001 & 0.0002 \\
\hline$\times$ Number of annual sessions & 0.000 & 0.000 & 0.000 & 0.000 \\
\hline$\times$ Number of illnesses & -0.0002 & 0.0002 & -0.0002 & 0.0001 \\
\hline$\times$ Sessions at home & -0.003 & $0.000 * * *$ & -0.002 & $0.000 * * *$ \\
\hline Number of patients & 12,728 & & 13,045 & \\
\hline Number of observations & $1,602,202$ & & $1,671,001$ & \\
\hline BIC & $70,544.97$ & & $76,009.07$ & \\
\hline Pseudo $R^{2}$ & 0.400 & & 0.378 & \\
\hline
\end{tabular}

Estimated coefficients are marginal utilities. Interactions on patient characteristics with distance ${ }^{2}$ are not reported (available from the authors)

${ }^{*} p<0.05 ; * * p<0.01 ; * * * p<0.001$
$\Delta P_{j d t}=\beta_{0}+\beta_{1} R_{j t}^{d}+\beta_{2} H_{j d t}+\beta_{3} Z_{j t}+\beta_{4} X_{p m t}+\varepsilon_{j d t}$

where the dependent variable $\Delta P_{j d t}$ is the difference in provider $j$ 's prices between two competitive biddings. The risk measure $R_{j t}^{d}$ in the model is the provider $j$ 's distance to the threshold in the previous round, calculated using the quality-price scores. The motivation for explaining price differences with the distance to the threshold is that we are not only interested in the price-level in general, but to investigate whether providers learned that they could have offered higher prices in the previous procurement. In both of the models we control for competition $H_{j d t}$, which is calculated using predicted patient flows. We also include vector $Z_{j t}$, which controls for providers' quality, capacity, premises, experience and business type, as well as vector $X_{d m t}$, which includes the number of potential patients in municipality $m$ as demand-side indicator and rents in postcode $p$ as supplyside indicator. These supply and demand-side factors have been shown to influence prices in previous empirical literature $[25,33]$. Finally, $\varepsilon_{j d t}$ is the error term of the models.

\section{Results}

\section{Descriptive evidence}

Table 1 shows the descriptive statistics of the accepted and rejected providers in the studied competitive biddings. The average price of accepted providers was 33.4 euros in 2003 , increased to 39.3 euros in 2006 , to 47.5 euros in 2010 and finally to 57.8 euros in 2014 . Moreover, the difference between the lowest and highest prices increased from 25 euros in 2003 to 82 euros in 2014. Most of the providers have participated in several competitive biddings, and 
Table 5 Regression results: Ln (Price)

\begin{tabular}{|c|c|c|c|c|c|c|}
\hline & \multicolumn{3}{|l|}{2010} & \multicolumn{3}{|l|}{2014} \\
\hline & Model 1 & Model 2 & Model 3 & Model 1 & Model 2 & Model 3 \\
\hline Rejections & $\begin{array}{l}-0.004 \\
(0.015)\end{array}$ & $\begin{array}{l}-0.028^{*} \\
(0.014)\end{array}$ & $\begin{array}{l}-0.020 \\
(0.013)\end{array}$ & $\begin{array}{l}-0.078^{* * * *} \\
(0.018)\end{array}$ & $\begin{array}{l}-0.071^{* * *} \\
(0.018)\end{array}$ & $\begin{array}{l}-0.054 * * \\
(0.017)\end{array}$ \\
\hline - Ln(Predicted HHI) & & $\begin{array}{l}-0.079 * * * \\
(0.011)\end{array}$ & $\begin{array}{l}-0.079 * * * \\
(0.010)\end{array}$ & & $\begin{array}{l}-0.034 * * * \\
(0.009)\end{array}$ & $\begin{array}{l}-0.026^{* * *} \\
(0.008)\end{array}$ \\
\hline Quality & & & $\begin{array}{l}0.004 * * * \\
(0.0003)\end{array}$ & & & $\begin{array}{l}0.008 * * * \\
(0.001)\end{array}$ \\
\hline Premises & & & $\begin{array}{l}0.000 \\
(0.018)\end{array}$ & & & $\begin{array}{l}-0.028 \\
(0.017)\end{array}$ \\
\hline Capacity & & & $\begin{array}{l}0.0002 * \\
(0.0001)\end{array}$ & & & $\begin{array}{l}0.0002 * \\
(0.0001)\end{array}$ \\
\hline New & & & $\begin{array}{l}0.056 * * * \\
(0.013)\end{array}$ & & & $\begin{array}{l}0.050 * * * \\
(0.013)\end{array}$ \\
\hline Rent & & & $\begin{array}{l}0.012 * * * \\
(0.002)\end{array}$ & & & $\begin{array}{l}0.005^{*} \\
(0.002)\end{array}$ \\
\hline Potential demand & & & $\begin{array}{l}0.000 \\
(0.000)\end{array}$ & & & $\begin{array}{l}0.000 \\
(0.000)\end{array}$ \\
\hline Business-type & No & No & Yes & No & No & Yes \\
\hline$N$ & 1202 & 1202 & 1202 & 1187 & 1187 & 1187 \\
\hline$R^{2}$ & 0.0001 & 0.049 & 0.278 & 0.018 & 0.030 & 0.196 \\
\hline
\end{tabular}

OLS estimates of Eq. (5) where the dependent variable is $\operatorname{Ln}$ (Price)

HHI Herfindahl-Hirschman Index

$* p<0.05 ; * * p<0.01 ; * * * p<0.001$ the proportion of new providers has been around $15 \%$ in each procedure ${ }^{15}$ On average, these experienced providers increased their prices by 5.5 euros 2006, 8.1 euros in 2010 and 10.1 euros in 2014. Providers also increased their annual capacity from an average of 18 annual patients in 2006 to 41 in $2014 .{ }^{16}$ The data show that even though the districts did not implement a systematic capacity-rule for acceptance, the average price of the rejected providers has been higher and quality lower compared to the accepted providers in each procurement. Thus, it seems that the districts only rejected the very few inefficient bids that they received. Also, more than half of the rejected providers were new providers and had a smaller number of existing patients compared to the accepted providers. These providers were most likely the easiest to reject as they had no existing patient relationships.

\section{Regression results}

The main regression results on the effects the risk of rejection has on prices are presented in Table 5. The risk of

\footnotetext{
15 Altogether the data includes 2023 different providers, 36\% of which participated in all of the four procurements.

16 All of the districts did not include capacity in their quality-price score tables in 2006.
}

rejection is measured as whether the provider was located in an area where at least one bid was rejected in the previous competitive bidding. The results show that higher risk had small and statistically weak but negative effects on prices in the 2010 competitive bidding. However, previously made rejections decreased prices by more than 5\% in 2014. Thus, the results indicate that rejecting at least one provider maintains a credible risk of rejection and enhances competitive pressure. We have two main explanations why increased risk did not have statistically as strong effects on prices in 2010 as in 2014. First, many of the districts merged between 2006 and 2010, and providers might have anticipated that new geographically larger districts would reject some of the providers. Second, the results indicate that the providers started to learn that the risk of rejection is very low within their district, and this finally actualized in 2014, when providers in areas where no rejections were previously made offered higher prices.

Table 6 shows the results regarding the effect of providers' previous distance to the rejection threshold on their price difference between the two competitive biddings. The results show that an increase of one quality-price point from the rejection threshold increased prices by more than 0.15 euros in 2010 and 0.06 euros in 2014. Thus, providers that were further away from the rejection threshold offered higher prices in the next competitive bidding. This indicates 
Table 6 Regression results: $\Delta$ Price

\begin{tabular}{|c|c|c|c|c|c|c|}
\hline & \multicolumn{3}{|l|}{2010} & \multicolumn{3}{|l|}{2014} \\
\hline & Model 1 & Model 2 & Model 3 & Model 1 & Model 2 & Model 3 \\
\hline Distance to threshold & $\begin{array}{l}0.165^{* * *} \\
(0.023)\end{array}$ & $\begin{array}{l}0.174 * * * \\
(0.023)\end{array}$ & $\begin{array}{l}0.153 * * * \\
(0.024)\end{array}$ & $\begin{array}{l}0.073 * * * \\
(0.020)\end{array}$ & $\begin{array}{l}0.079 * * * \\
(0.020)\end{array}$ & $\begin{array}{l}0.060 * * \\
(0.021)\end{array}$ \\
\hline -Ln (Predicted HHI) & & $\begin{array}{l}-1.609 * * * \\
(0.344)\end{array}$ & $\begin{array}{l}-1.607 * * * \\
(0.344)\end{array}$ & & $\begin{array}{l}-0.789 * \\
(0.348)\end{array}$ & $\begin{array}{l}-0.636 \\
(0.362)\end{array}$ \\
\hline Quality & & & $\begin{array}{l}0.050 * * * \\
(0.012)\end{array}$ & & & $\begin{array}{l}0.080 * * \\
(0.028)\end{array}$ \\
\hline Premises & & & $\begin{array}{l}-0.121 \\
(0.763)\end{array}$ & & & $\begin{array}{l}-1.442 * \\
(0.725)\end{array}$ \\
\hline Capacity & & & $\begin{array}{l}0.001 \\
(0.004)\end{array}$ & & & $\begin{array}{l}-0.001 \\
(0.004)\end{array}$ \\
\hline Rent & & & $\begin{array}{l}0.178 * \\
(0.082)\end{array}$ & & & $\begin{array}{l}-0.243^{* *} \\
(0.092)\end{array}$ \\
\hline Potential demand & & & $\begin{array}{l}-0.0002 \\
(0.0002)\end{array}$ & & & $\begin{array}{l}0.0003 \\
(0.0002)\end{array}$ \\
\hline Business-type & No & No & Yes & No & No & Yes \\
\hline $\mathrm{N}$ & 964 & 964 & 964 & 934 & 934 & 934 \\
\hline $\mathrm{R}^{2}$ & 0.061 & 0.082 & 0.114 & 0.014 & 0.019 & 0.055 \\
\hline
\end{tabular}

OLS estimates of Eq. (6) where the dependent variable is $\Delta$ Price

$H H I$ Herfindahl-Hirschman Index

$* p<0.05 ; * * p<0.01 ; * * * p<0.001$ that providers learned to evaluate their optimal bids, taken their quality, and noticed that they could take a bigger risk in the next round. Thus, providing providers information regarding their optimal prices and risk of rejection enabled strategic bidding behavior, and increased the overall pricelevel of the service.

In both of the regression analyses we also include competition, measured as a negative natural logarithm of a HHI that is based on predicted patient flows. Regarding the analysis on prices (Table 5), the coefficients for competition are negative and statistically significant both in 2010 and 2014 across all of the models. This result indicates that prices were lower in districts that are more competitive. Table 9 (in the Appendix) provides similar regression results using the competition measure based on actual patient flows. This analysis shows that the results regarding the effects of the risk of rejection on prices are robust across the two different measures of market structure. In contrast with the previous work by Pekola et al. [9], our results show that greater competition decreases prices. The difference between the results is most likely due to different measures of competition, as their paper measures the degree of competition using the number of physiotherapy providers in a given municipality.

The main results regarding both of the regression analyses are rather robust across all model specifications, including when we control for various provider and area-level attributes. The results in Table 5 show that providers with greater quality and larger capacity offered higher prices. Also, new providers and providers in more expensive areas offered higher prices. Further, we also tested whether the number of rejections had an effect on prices. These results confirmed that the more providers the district rejected, the lower the price level was in the next round. We also analyzed models including all control variables except quality, because quality and price are likely to be related, even though the measured quality in this study is based on long-term quality investments. This analysis did not change the main results of the study. Finally, we analyzed whether the effect of distance to the threshold was stronger in the districts that made rejections, but found no statistically significant evidence.

\section{Counterfactual policy analysis}

We analyze the effects of implementing a capacity-rule for acceptance in the 2014 competitive bidding for the 2015-2018 contract period. We investigate two capacityrules that are based on the number of patients in the district added by 10 or 100 percent. ${ }^{17}$ From a practical point of view,

\footnotetext{
17 In the 2018 competitive bidding, Kela used a capacity-rule based on number of patients in 2017 added by 10 percent, but accepting at least three providers in each municipality to ensure short travel distances.
} 
the scenarios take into account potential market exits and increasing demand during the contract periods. We perform the analysis using the following three steps: first, we create the counterfactual pools by including all providers in the quality-price lists until the capacity rule is reached. ${ }^{18}$ Second, we examine how patients distribute among providers in the counterfactual pools. We predict the choice of provider among patients who are required to switch, because their initial provider is not included in the counterfactual pool. For the predicted choices we use the estimates from the choice model in 2015 (see Table 4). In these predictions we replace the variable capacity with providers' remaining free capacity, to take into account that switching patients would be less likely to choose a provider with only little free capacity. The provider with the greatest probability is considered as the chosen one. In the final step we calculate expected annual costs and travel distances per patient at their chosen provider.

Table 7 presents the results of the counterfactual scenarios calculated in 2015 . Implementing a $100 \%$ capacity-rule results in 586 accepted providers and 601 rejected providers. The average price of the accepted providers is 2.3 euros lower and the average quality 3.6 points higher compared to the actual pools. Because a large number of providers are rejected, $35 \%$ of the patients are required to switch providers. However, compared to the actual choices in 2015, an average patient visits a provider with 2.4 points higher quality located only $0.7 \mathrm{~km}$ further from their home. Patientlevel annual costs are on average 104 euros less than actual costs in 2015, and the total annual costs decrease by 1.35 million euros. This represents annual savings of $2 \%$ points. Table 7 also shows estimations for the stricter $10 \%$ capacity rule, where only 353 providers are accepted and $60 \%$ of the patients are required to switch providers. An average patient visits a provider with 3.7 points higher quality located $3.7 \mathrm{~km}$ further away from home, compared to actual choices in 2015. Implementing the rule results in annual savings of 2.3 million euros.

Our results show that implementing a capacity-rule would have resulted in large fiscal savings and higher quality of care in the 2015-2018 contract period. ${ }^{19}$ On the other hand,

\footnotetext{
18 For example the district of Helsinki was responsible for organizing the service for 985 patients in 2014. The district received bids from 72 providers with a total capacity of 3471 in the 2014 competitive bidding for the contract period 2015-2018. The district accepted all 72 providers into the pool. Using the 10 percent capacity-based rule we create a counterfactual pool where the first providers in the quality-price list are accepted until the required capacity of 1084 is reached. In this example, the first 23 providers are accepted in the counterfactual pool and the remaining 49 providers in the list are not included.

19 We performed a similar analysis for the 2010-2014 contract period. The results are similar to the 2015-2018 period, but potential
}

many patients would have been required to switch providers and travel longer distances. Our analysis for the direct fiscal savings can be viewed as lower bound estimates, because rejecting a large number of providers would have probably kept the initial level of the bids lower. Also, the two districts that piloted a fixed price were also excluded from this analysis. Further, the districts have a legal possibility to negotiate direct contracts between patients and providers located in areas with few alternatives. Using these direct contracts can further reduce unnecessary forced switching and increased travel distances in cases where a provider is rejected from the pool of providers but might be necessary for a small portion of patients nearby.

\section{Discussion}

Competitive bidding can be a powerful cost containment mechanism in health services. Even though the use of competitive biddings has increased, there is very little empirical evidence regarding the characteristics of regular competitive biddings in health care. In this study we analyze competitive biddings that were organized repeatedly every 4 years by Kela's insurance districts to acquire multiple providers for a physiotherapy service in their area. The districts rejected only very few providers because of a lack of financial incentives to use a systematic acceptance rule, and because the districts did not want to terminate established relationships between patients and their usual providers. We analyze whether these features had an effect on providers' bidding behavior.

Our descriptive analysis regarding the competitive biddings in 2003, 2006, 2010 and 2014 shows that the overall price-level and dispersion of the bids increased heavily during the period. The regression analysis provides further evidence regarding bidding behavior. We show that providers that are located in areas where at least one bid was rejected in the previous competitive bidding offered 5.5\% lower prices in the 2014 competitive bidding. Further, we show that providers that were far above the rejection threshold increased their price bids more than providers closer to the threshold. These results indicate that providers learned the institutional features of the competitive bidding and started to behave more strategically. Finally, we perform counterfactual analysis, which shows that using a systematic $100 \%$ capacity-rule of acceptance would have resulted in direct fiscal savings of at least 5.4 million euros in the 2015-2018 contract period. Even though rejecting a larger number of

\section{Footnote 19 (continued)}

direct fiscal savings would have been lower because the overall pricelevel of the bids was lower. The results are available from the authors. 


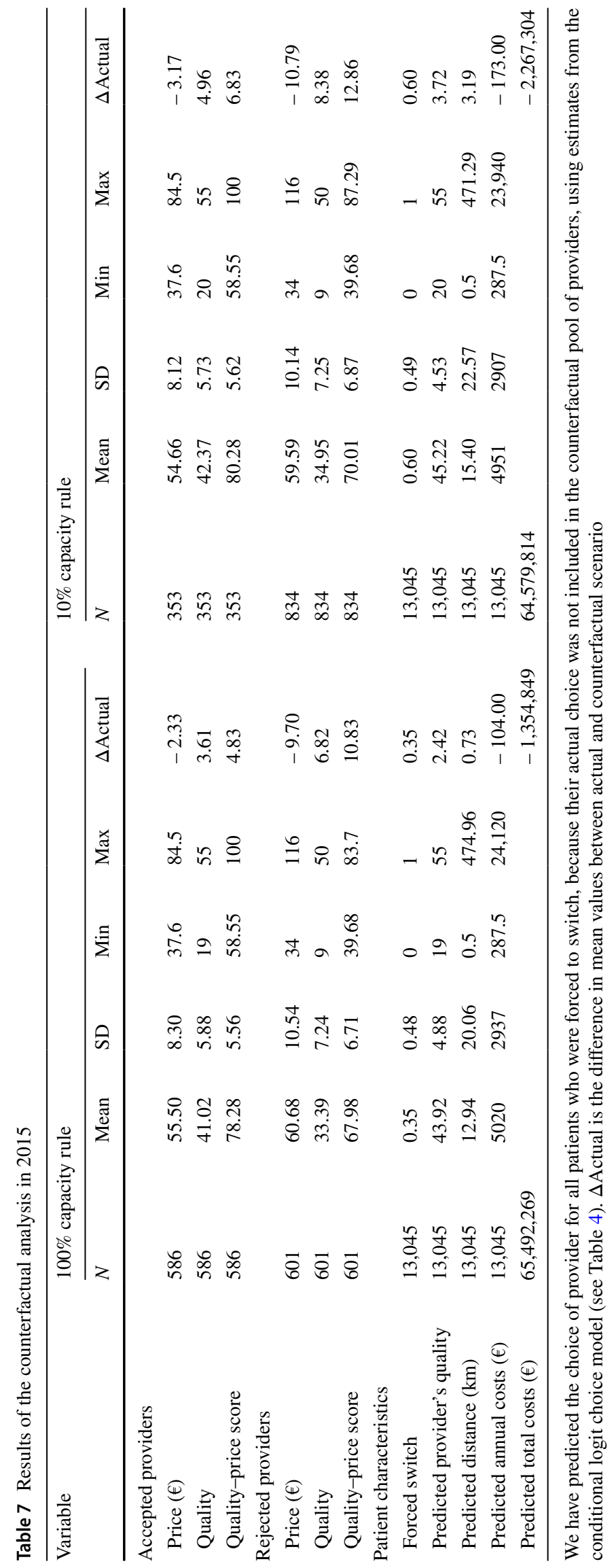


providers might have resulted into forced switching of providers and longer travel distances, patients would have also received a higher quality of care.

Our study offers some important policy implications in regularly arranged competitive biddings with multiple winners in health care. We show that unless a clear rejection threshold is used, the competitive pressure regarding prices does not exist. Thus, the overall price-level increases when providers eventually learn that the risk of rejection is low. Applying a systematic capacity-rule of acceptance has two main features that increase efficiency of the services. First, the capacity-rule brings positive dynamic effects because the competitive pressure increases. Even though our analysis focuses only on price competition, it is likely that also quality competition increases as a result of a higher quality-price threshold for acceptance. Second, the capacity-rule also has direct effects because only the most efficient providers with the greatest quality-price ratio are accepted in the pool of providers.

The results raise some challenges for practical decisionmaking. It might be difficult for the service organizer to suddenly reduce the number of accepted providers for two main reasons. First, rejecting providers might end a large number of existing relationships between patients and providers. Second, it is likely that the travel distances would increase as a result of the rejections. In 2018 Kela renewed its procurement practices. Five large districts that organized the procurement were instructed to accept providers based on the number of patients in their area and the capacity of the providers added by around $10 \%$. Thus, the main policy recommendation of this paper was placed into practise. However, Kela did receive a lot of negative feedback. One possible solution to avoid the negative features is to apply a fixedprice and accept all providers that meet the minimum quality standards. This requires information about the supply-side costs to determine the right price-level. A fixed price might also not encourage providers to invest in their quality beyond the minimum necessary level, unless patients have freedom of choice and quality information about the providers.

Acknowledgements Open access funding provided by the Social Insurance Institution of Finland (Kela). This study was financed through funds of the Act on the Social Insurance Institution of Finland's Rehabilitation Benefits and Rehabilitation Allowance Benefits (L556/2005, $12 \S)$. The authors would like to thank all Kela personnel who helped to gather the data.

\section{Compliance with ethical standards}

Conflict of interest Pitkänen and Jauhiainen receive a salary from Kela, which organizes and finances the studied rehabilitation services and the competitive biddings. The paper represents the views of the authors and does not necessarily represent the official views of Kela.

Open Access This article is licensed under a Creative Commons Attribution 4.0 International License, which permits use, sharing, adaptation, distribution and reproduction in any medium or format, as long as you give appropriate credit to the original author(s) and the source, provide a link to the Creative Commons licence, and indicate if changes were made. The images or other third party material in this article are included in the article's Creative Commons licence, unless indicated otherwise in a credit line to the material. If material is not included in the article's Creative Commons licence and your intended use is not permitted by statutory regulation or exceeds the permitted use, you will need to obtain permission directly from the copyright holder. To view a copy of this licence, visit http://creativecommons.org/licenses/by/4.0/.

\section{Appendix}

See Appendix Fig. 3; Tables 8, 9. 


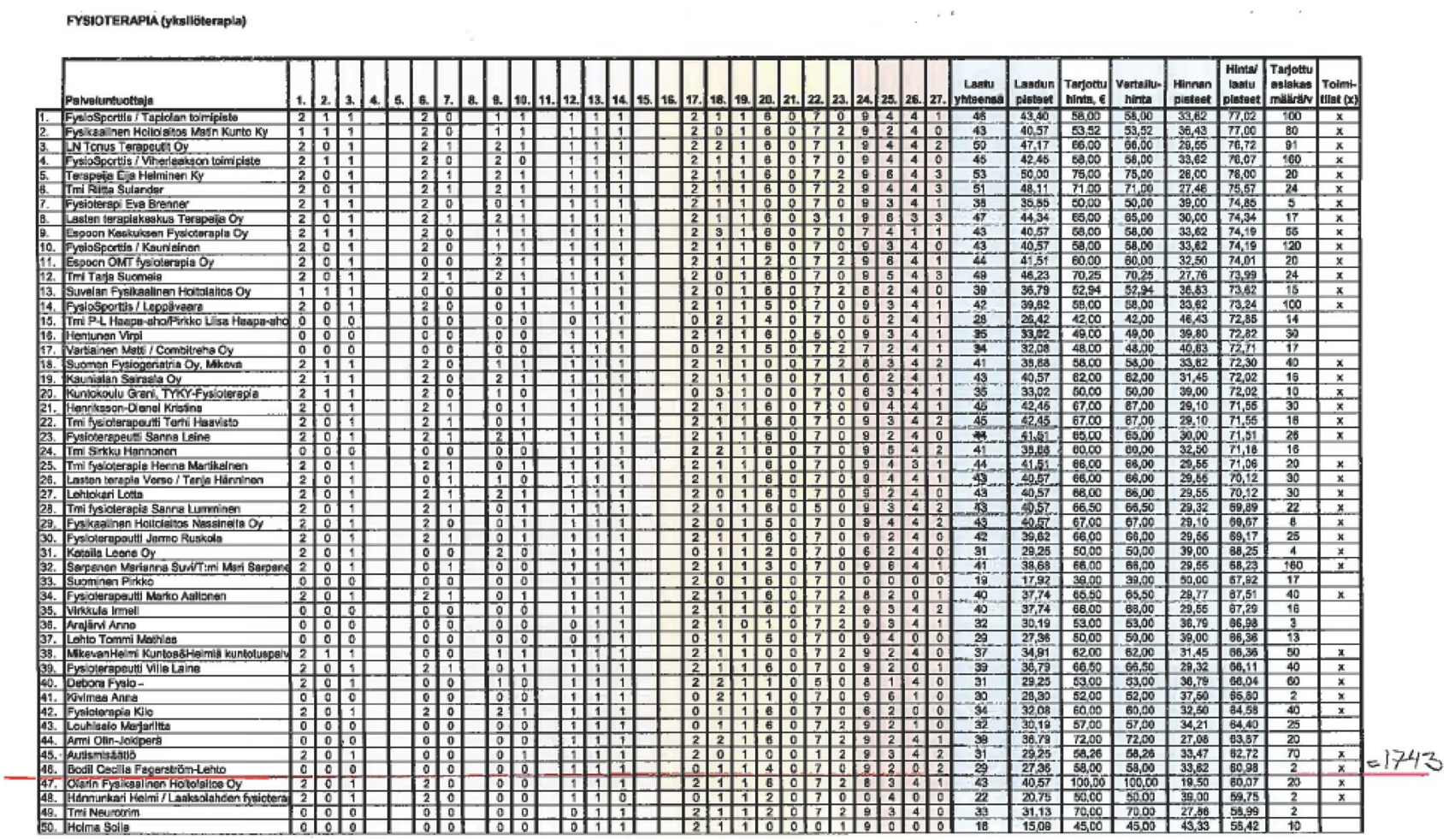

Fig. 3 An example of the quality-price score table in the Espoo district in the 2014 competitive bidding. The red line presents the rejection threshold that the insurance district implemented based on the quality-price scores and the local demand for the service. The district accepted 46 providers as service providers with a total capacity for 1743 patients. Providers below the threshold were not offered a contract
Table 8 Descriptive statistics of the districts with and without rejections in 2006 and 2010

\begin{tabular}{|c|c|c|c|c|c|c|c|c|c|c|}
\hline \multirow[t]{2}{*}{ Variable } & \multicolumn{5}{|c|}{ Districts with rejections } & \multicolumn{5}{|c|}{ Districts without rejections } \\
\hline & $N$ & Mean & SD & Min & $\operatorname{Max}$ & $N$ & Mean & SD & Min & $\operatorname{Max}$ \\
\hline \multicolumn{11}{|l|}{2006} \\
\hline Bidders & 5 & 27.40 & 12.40 & 17 & 46 & 48 & 25.81 & 20.78 & 2 & 125 \\
\hline Quality-price threshold & 5 & 67.79 & 7.04 & 59.78 & 77.01 & 48 & 67.48 & 9.51 & 44.38 & 93.16 \\
\hline Patients & 5 & 278.60 & 199.88 & 107 & 611 & 48 & 234.06 & 152.60 & 32 & 853 \\
\hline \multicolumn{11}{|l|}{2010} \\
\hline Bidders & 3 & 37.67 & 10.50 & 27 & 48 & 24 & 45.38 & 17.96 & 6 & 85 \\
\hline Quality-price threshold & 3 & 71.47 & 7.37 & 63.80 & 78.50 & 24 & 60.41 & 8.06 & 40 & 73.5 \\
\hline Patients & 3 & 362.00 & 142.52 & 233 & 515 & 24 & 489.50 & 201.23 & 49 & 942 \\
\hline
\end{tabular}


Table 9 Regression results: Ln (Price)

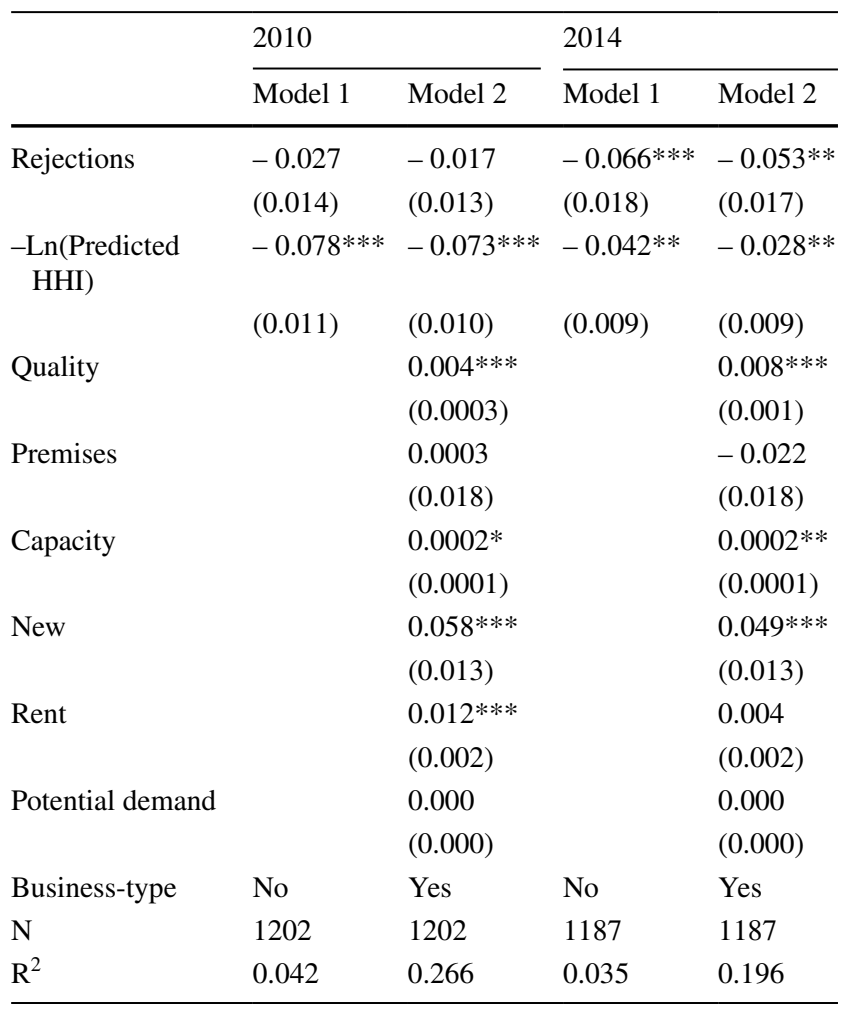

OLS estimates of Eq. (5) where the dependent variable is Ln (Price)

HHI Herfindahl-Hirschman Index

$* p<0.05 ; * * p<0.01 ; * * * p<0.001$

\section{References}

1. European Commission. Public Procurement. https://ec.europa.eu/ growth/single-market/public-procurement_en (2018) Accessed 7 June 2018

2. Barros, P.P., Brouwer, W.B.F., Thomson, S., Varkevisser, M.: Competition among health care providers: helpful of harmful? Eur J. Health Econ. 17, 229-233 (2016)

3. Arrow, K.: Uncertainty and the welfare economics of medical care. Am Econ Rev. 53, 941-973 (1963)

4. Katzman, B., McGeary, K.A.: Will competitive bidding decrease Medicare prices? Southern Econ J. 74, 839-856 (2008)

5. Mougeot, M., Naegelen, F.: Using auctions for contracting with hospitals when quality matters. Int J Health Care Finance Econ $\mathbf{3}$, 5-23 (2003)

6. Song, Z., Landrum, M.B., Chernew, M.E.: Competitive bidding in Medicare: Who benefits from competition? Am J. Managed Care. 18, 546-552 (2012)

7. Song, Z., Landrum, M.B., Chernew, M.E.: Competitive biddings in medicare advantage: effect of benchmark changes on plan bids. J. Health Econ. 32, 1301-1312 (2013)

8. Dranove, D.: Health care markets, regulators and certifiers. In: Pauly, M.V., McGuire, T.G., Barros, P.P. (eds.) Handbook of Health Economics, vol. 2, pp. 639-690. Elsevier, UK (2012)

9. Pekola, P., Linnosmaa, I., Mikkola, H.: Does competition have an effect on price and quality in physiotherapy? Health Econ. 26, 1278-1290 (2017)
10. Higuera, L., Carlin, C.S., Dowd, B.: Narrow provider networks and willingness to pay for continuity of care and network breadth. J. Health Econ. 60, 90-97 (2018)

11. Gutacker, N., Siciliani, L., Moscelli, G., Gravelle, H.: Choice of hospital: Which type of quality matters? J. Health Econ. 50, 230-246 (2016)

12. Varkevisser, M., van der Geest, S., Schut, F.T.: Do patients choose hospitals with high quality ratings? Empirical evidence from the market for angioplasty in the Netherlands. J. Health Econ. 31, 371-378 (2012)

13. Propper, C., Wilson, D., Burgess, S.: Extending choice in English health care: the implications of the economic evidence. J. Social Policy. 35, 537-557 (2006)

14. Vrangbaek, K., Robertson, R., Winblad, U., Van de Bovenkamp, H., Dixon, A.: Choice policies in Northern European health systems. Health Econ Policy Law 7, 47-71 (2012)

15. Santos, R., Gravelle, H., Propper, C.: Does quality affect patients' choice of doctor? Evidence from England. Econ J. 127, 445-494 (2016)

16. Chalkley, M., Malcomson, H.M.: Contracts and competition in the N.H.S. In: Culyer, A.J., Wagstaff, A. (eds.) Reforming health care systems: experiments with the NHS, pp. 65-87. Edward Elgar, Chelterham (1996)

17. Antos, J.R., Pauly, M.V., Wilensky, G.R.: Bending the cost curve through market-based incentives. N Engl J. Med. 366, 879-881 (2012)

18. Klemperer, P.: What really matters in auction design. J. Econ Perspect. 16, 169-189 (2002)

19. McCombs, J.S., Christianson, J.B.: Applying competitive bidding to health care. J Health Polit Policy Law 12, 703-722 (1987)

20. Skrzypacz, A., Hopenhayn, H.: Tacit collusion in repeated auctions. J. Econ Theory. 114, 153-169 (2004)

21. Suomen Virallinen Tilasto. Kelan kuntoutustilasto 2015. https:// www.kela.fi/vuositilastot_kelan-kuntoutustilasto (2016). Accessed 22 February 2018

22. Tay, A.: Assessing competition in hospital care markets: the importance of accounting for quality differentiation. RAND J. Econ. 34, 786-814 (2003)

23. Forder, J., Allan, S.: The impact of competition on quality and prices in the English care homes market. J. Health Econ. 34, 73-83 (2014)

24. Dranove, D., Ody, C.: 2015. Evolving measures of provider market power. Am J. Health Econ. 2, 145-160 (2015)

25. Cooper, Z., Craig, S.V., Gaynor, M., Van Reenen, J.: The price ain't right? Hospital prices and health spending on the privately insured. Q. J. Econ. 134, 51-107 (2019)

26. Kessler, D., McClellan, M.: Is hospital competition socially wasteful? Q. J. Econ. 115, 577-615 (2002)

27. Cooper, Z., Gibbons, S., Jones, S., McGuire, A.: Does hospital competition save lives? Evidence from the English NHS patient choice reforms. Econ. J. 121, F228-F260 (2011)

28. Cookson, R., Laudicella, M., Li Donni, P.: Does hospital competition harm equity? Evidence from the English National Health Service. J. Health Econ. 32, 410-422 (2013)

29. McFadden, D.: Conditional Logit Analysis of Qualitative Choice Behavior. In: Zarembka, P. (ed.) Frontiers in Econometrics, pp. 105-142. Academic Press, New York (1974)

30. Town, R.J., Vistnes, G.: Hospital competition in HMO networks. J. Health Econ. 20, 733-753 (2001)

31. Varkevisser, M., van der Geest, S.A., Schut, F.T.: Assessing hospital competition when prices don't matter to patients: the use of time-elasticities. Int J Health Care Finance Econ 10, 43-60 (2010)

32. Capps, C., Dranove, D., Satterthwaite, M.: Competition and market power in option demand markets. RAND J. Econ. 34, 737-763 (2003) 
33. Gaynor, M., Seider, H., Vogt, W.B.: The volume-outcome effect, scale economies, and learning-by-doing. Am Econ Rev. 95, 243 247 (2005)
Publisher's Note Springer Nature remains neutral with regard to jurisdictional claims in published maps and institutional affiliations. 